\title{
Proyecto de normas transnacionales \\ del proceso civil $\left({ }^{1}\right)$
}

\section{Redactado por \\ Profesor Geoffrey C. Hazard, Jr. Profesor Michele Taruffo}

\section{A. Competencia y Jurisdicción Personal}

1. Procesos a los que aplican estas normas (Ámbito de aplicación normativa).-

(a) Sujeto a las disposiciones constitucionales, y a las de derecho interno que no contravengan expresamente las disposiciones previstas por estas normas, los Tribunales de Justicia de un Estado parte, las presentes normas deberán ser aplicadas de modo vinculante y preferente en todo proceso que surja en su ámbito de competencia territorial en toda compra-venta, arrendamiento, préstamo, inversión, o cualesquiera otra modalidad o denominación jurídica de

Versión libre revisada (30.abril.99) por el Dr. Aníbal Quiroga León, Profesor Principal de
la Facultad de Derecho de la Pontificia Universidad Católica del Perú, Miembro de la Aso-
ciación Internacional de Derecho Procesal y del Instituto Iberoamericano de Derecho Proce-
sal, y Editor General de la Revista "DERECHO-PUC" -con la autorización del Prof. Antonio
Gidi, Assistant Reporter, sobre la base de la traducción preparada por la Prof. Evaluz Cotto
de la Escuela de Derecho de la Universidad de Puerto Rico, quien en esta tarea recibió la
valiosa colaboración de su asistente de investigación, la estudiante de Derecho Srta. Cindy
Badano. Favor enviar sus críticas y sugerencias en español o en inglés a la siguiente dirección:

THE AMERICAN LAW INSTITUTE

Transnational Rules of Civil Procedure

4025 Chestnut Street

Philadelphia PA 19104-3099

Fax: +1(215) 243-1664

Transrules@ali.org

http://www.ali.org/ali/transrules.htm 
todo negocio comercial o mercantil, cuando se presenten cualesquiera de los siguientes supuestos alternativos:

(1) En los que un demandante o un demandado sean residentes habituales de diferentes Estados; o

(2) Cuando la pretensión demandada se refiera a bienes, muebles o inmuebles, localizados en un Estado, en relación con los cuales un demandante que es residente habitual de otro Estado hace un reclamo judicial de propiedad o de gravamen mobiliario a su favor.

(b) Una corporación o persona jurídica, cualesquiera sea su clase o denominación, tal como sociedad anónima, sociedad anónima abierta, sociedad anónima cerrada, sociedad de hecho, asociación no incorporada, asociación sin fines de lucro, sociedad u otra entidad organizada se considerará residente habitual del Estado en el cual se constituyó, registro u organizó, o del Estado donde mantiene sus oficinas administrativas principales.

(c) La participación de terceros legitimados, sea como parte demandante, parte demandada, o tercero litisconsorte, se determinará de acuerdo con lo dispuesto en el Art. 2.

(d) Salvo acuerdo expreso de las partes que no sean residentes habituales del Estado que determine la aplicación de estas normas, el proceso deberá llevarse a cabo de acuerdo con la ley procesal ordinaria del foro que les corresponda conforme a su ley interna.

(e) La ley interna puede incorporar expresamente a la competencia legislativa de estas Normas otros asuntos civiles no originalmente previsto por estas disposiciones, las que se constituirían en imperativas en el Estado de que se trate.

\section{Jurisdicción Personal y Acumulación}

(a) Se podrá iniciar válidamente un proceso bajo estas normas en los Tribunales de Justicia de un Estado si:

(1) Ello ha sido expresamente convenido por acuerdo previo entre las partes;

(2) El demandado está sujeto a la autoridad judicial por imperio de 
la ley interna que regule la jurisdicción personal o por convención internacional de la cual el Estado sea signatario;

(3) Donde el bien inmueble esté localizado cuando la competencia se basa en lo dispuesto en el Art. 1(a)(2).

(b) Se podrá extender la jurisdicción de estas normas sobre una persona cuando:

(1) Tiene un legítimo interés legal en el proceso, pretensión o asunto de que se trate, y solicite expresamente intervenir en este; o

(2) Debe participar en el proceso en interés de que se alcance una decisión justa y eficaz, si:

A) La persona interesada está sujeta a la autoridad judicial del Estado; y

B) El Tribunal Judicial determine que la decisión no se hará efectiva hasta que la persona de que se trata no esté presente, o que la participación de esa persona será útil a los intereses de la justicia.

(c) Una persona deberá ser considerada como parte del proceso:

(1) Si el Tribunal Judicial tiene jurisdicción sobre esa persona. La persona debe ser debidamente emplazada según lo dispuesto en el Art. 7.

(2) Si la persona no está sujeta a la jurisdicción del Tribunal Judicial, deberá ser adecuadamente notificada con una copia de la demanda y otras alegaciones, y citada a comparecer en plazo razonable.

(d) La aplicación de estas Normas no se verá afectada por la participación de terceros, cualesquiera su denominación u origen, excepto según lo dispuesto en el Art. 1(d). Si de modo previo a la audiencia plenaria se permite la acumulación subjetiva de un tercero cuya presencia como litisconsorte sea necesaria, la norma 1 será de plena aplicación en el proceso, aplicándose imperativamente estas Normas, a menos que el Tribunal Judicial ordene lo contrario en interés de la adecuada Administración de Justicia.

(e) Cualquier persona, pública o privada, podrá presentar un testimonio verbal o escrito amicus curiae, en calidad de perito, y que in- 
cluya datos, información, comentarios y consideraciones que puedan ser relevantes a la controversia de que se trate y que tenga por finalidad el alcanzar una decisión justa.

\section{Competencia}

El proceso se iniciará ante el Tribunal de primera instancia de la localidad que corresponda según las Normas de competencia del derecho interno del correspondiente Estado.

\section{Composición del tribunal}

El Tribunal Judicial estará integrado según se prevea en la ley interna del Estado de que se trate, excepto cuando:

(a) El Tribunal Judicial estará compuesto por tres jueces, cuando menos, si el derecho interno lo permite;

(b) El Tribunal Judicial, con el consentimiento de las partes, podrá designar no más de dos peritos imparciales, que podrán ser expertos en la materia o asunto en disputa. Al escoger a los peritos, el Tribunal Judicial deberá escuchar previamente a las partes. Los peritos tienen voz, pero no tienen voto; pero en sus deliberaciones el Tribunal Judicial puede consultar con ellos en las deliberaciones reservadas. Los honorarios o gastos de estos peritos serán pagados por las partes de modo proporcional, o según disponga el Tribunal Judicial.

\section{Principios de interpretación}

(a) Estas normas se interpretarán de manera tal que se propenda de modo favorable a la justicia sustantiva y procesal, tomando en cuenta en lo que fuere pertinente el medio cultural y los usos y costumbres legales de los litigantes.

(b) A cada parte se concederá el derecho a presentar su caso de modo apropiado, dentro de un plazo razonable y tendrá derecho a recibir igual trato en el proceso $\left(^{2}\right)$. 
(c) Los procesos tendrán por finalidad esencial satisfacer las expectativas razonables de justicia solucionando el conflicto de intereses de modo inmediato y procurando la paz social en la comunidad de modo mediato, debiendo ser resueltos dentro de un plazo y costo razonables, sin dilaciones indebidas, ni gastos innecesarios $\left(^{3}\right)$.

(d) El Tribunal Judicial requerirá de todos los partícipes del proceso una conducta procesal apropiada, profesional, conforme a los principios de la buena fe y lealtad procesal.

(e) Las restricciones procesales y las penalidades contra las partes, los terceros y los demás intervinientes en el proceso se aplicarán de modo razonable y de acuerdo a su finalidad.

\section{Procedimiento para determinar el foro y la autoridad general del tribunal}

De conformidad con las disposiciones del Art. 5, la ley procesal del foro interno del Estado de que se trate se aplicará a los asuntos que no estén atendidos por estas Normas, entre ellos, los plazos o términos de vencimiento previstos para los asuntos procesales. Además de la autoridad expresamente delegada por estas Normas, el Tribunal Judicial tiene plena autoridad para dirigir el proceso de que se trate y para tomar las decisiones más adecuadas a fin de cumplir con los intereses de la justicia.

\section{B. Procedimiento}

\section{Inicio del proceso}

(a) Un proceso se estimará iniciado de acuerdo con lo que determine las Normas del foro interno del Estado de que se trate. El proceso será designado como «Proceso Transnacional».

(b) Al momento de presentar la demanda, se cumplirá con notificar al demandado, o demandados, de acuerdo con la convenio interna-

engloba lo que aquí se quiere exponer. "Las partes tendrán, en los procesos regidos conforme a estas Normas, derecho al debido proceso legal, procesal y sustantivo». (N. del Traductor Prof. Aníbal Quiroga León).

3 Agregado por Prof. Aníbal Quiroga León. N. del Traductor. 
cional aplicable. Si no existe una convenio aplicable, se llevará a cabo la notificación mediante la transmisión de la copia de la demanda y una notificación de que el demandante elige proceder bajo estas Normas. La notificación indicará el apremio de que puede dictarse sentencia en rebeldía contra el demandado si éste no cumple con hacer la contestación a la demanda y comparecer en debida forma al proceso. La notificación de la demanda se redactará en el idioma del foro interno, además del idioma del Estado del cual el demandado es residente habitual.

\section{Demanda}

(a) El demandante expondrá de modo conciso los hechos en los cuales basa su demanda, los fundamentos legales de ésta, y la razón por la cual se pretende el proceso bajo estas Normas. La demanda especificará, dentro de lo razonable, el momento, lugar, partes, partícipes $y$ hechos relevantes que sean pertinentes a la pretensión del demandante. El demandante podrá modificar su demanda una vez presentada al Tribunal Judicial, de acuerdo con los términos que el Tribunal Judicial y el derecho interno disponga. El Tribunal Judicial concederá plazo razonable para enmendar la demanda, con conocimiento del demandado.

(b) El demandante presentará copias de todos los documentos e instrumentos públicos o privados en que fundamente su pretensión o sus reclamaciones. El demandante también enumerará a todos los testigos, sean o no parte, que se proponga utilizar para acreditar o fundamentar sus reclamaciones. La lista de testigos identificará a estas personas por nombre, ocupación, dirección y número telefónico.

(c) El demandante determinará el objeto de su pretensión jurídica, el modo de lograrlo, incluyendo el monto de la indemnización que se proponga reclamar, costas, costos, multas y penalidades, así como cualquier solicitud cautelar que la protección de su pretensión pudiere requerir.

\section{Contestación a la demanda y reconvención}

(a) El demandado contestará la demanda dentro de los sesenta (60) días calendarios siguientes a su notificación, admitiendo o negando las alegaciones en documento debidamente fundamentado. Ade- 
más, de presentar adecuadamente su exposición de los hechos y presentará sus excepciones y defensas previas. El término para contestar se podrá prorrogar por un período razonable por acuerdo entre las partes o por decisión del Tribunal Judicial a petición del demandado. En la contestación se contendrá, cuando menos:

(1) La negación expresa de las partes de la demanda que el demandado interesa controvertir;

(2) La admisión, con fundamentación adecuada, de las alegaciones que el demandado no interesa controvertir, según lo exponga;

(3) La exposición de los hechos de cualquier excepción o defensa previa y los fundamentos legales en que la sustenta.

(b) Las disposiciones de la Norma 8 respecto a la demanda son igualmente aplicables a la contestación de la demanda.

(c) El demandado puede presentar una reconvención para solicitar una pretensión que a su derecho corresponda contra el demandado, a fin que sea también resuelto por el mismo Tribunal Judicial en el mismo proceso, y una demanda contra su coparte o contra tercero legitimado, por ejemplo, un acción de nivelación, según lo permita la ley procesal del foro. El demandante y las partes adicionales someterán contestaciones a la reconvención, demanda contra coparte o demanda contra tercero.

(d) De acuerdo con la ley procesal del derecho interno, cualquier parte puede acumular partes adicionales que estén sujetas a la jurisdicción del Tribunal Judicial.

(e) Las alegaciones que no requieran una contradicción expresa se considerarán negadas. Las alegaciones que requieran una contradicción expresa se considerarán admitidas si no son negadas expresamente. Los hechos admitidos o considerados admitidos no necesitan ser probados, excepto según lo dispuesto en la Norma 10 (b) con respecto a la sentencia en rebeldía.

(f) Cualquier parte puede solicitar al Tribunal Judicial, o éste puede ordenar motu proprio (o exofficio), la presentación de alegaciones o contestaciones más específicas si así lo considerara necesario. Si una parte no presenta las alegaciones solicitadas, el Tribunal Judicial puede eliminar las alegaciones o contestaciones de la parte sobre este asunto. 
(g) El demandado puede en su contestación presentar las objeciones enumeradas en la Norma 13 (a). La presentación de una contestación o una reconvención no se implicará una renuncia al derecho a invocar dichas objeciones.

\section{Sentencia en rebeldía}

(a) El Tribunal Judicial expedirá Sentencia en rebeldía contra un demandado que no conteste, no comparezca, no presente una contestación sustancial, o que haya dejado manifiestamente de defenderse en alguna otra forma.

(b) Antes de expedir una Sentencia en rebeldía el Tribunal Judicial deberá:

(1) Asegurarse de que el demandado fue debidamente citado con la notificación del correcto modo legal. Si la demanda fue modificada, ésta será notificada nuevamente, bajo el mismo procedimiento, volviéndose a computar los plazos a partir de la modificación.

(2) Determinar si la demanda está bien fundamentada en cuanto a la existencia del derecho que se reclama en la pretensión, y lo que se solicita, incluyendo la determinación del monto de los daños a ser adecuadamente reparados.

(c) La prestación judicial que la sentencia en rebeldía conceda no podrá exceder los límites de la pretensión solicitado en la demanda.

(d) A una parte que comparece al Tribunal Judicial después del vencimiento del término provisto en estas Normas, pero antes de que se dicte sentencia en rebeldía, se le permitirá comparecer del modo apropiado si ofrece una justificación razonable para su tardanza.

\section{Oferta de transacción en un pleito transnacional}

(a) Una parte puede entregar a otra parte una oferta de transacción por escrito para transigir uno o más reclamos y los gastos relacionados con ello. La oferta se mantendrá vigente por sesenta (60) días, a menos que ésta se retire mediante un escrito entregado a quien se le hizo la oferta, previo a que esta parte entregue su aceptación. 
(b) La parte que recibió la oferta puede hacer una contra-oferta, que se mantendrá vigente por lo menos durante treinta (30) días. Si no se acepta la contra-oferta, la parte puede aceptar la oferta original, si ésta aún está vigente.

(c) Una oferta que no se retire ni se acepte antes de su expiración, se considerará rechazada.

(d) Una oferta no se divulgará, ni siquiera al Tribunal Judicial, antes de que se dicte sentencia, so pena de sanciones o desestimación con perjuicio o en rebeldía.

(e) Dentro del término de diez (10) días después de dictada la Sentencia, una parte puede divulgar la oferta al Tribunal Judicial. Si el Tribunal Judicial determina que la oferta o su rechazo fue irrazonable, éste impondrá las sanciones apropiadas, tomando en cuenta todas la circunstancias relevantes del caso.

(f) La sanción consistirá del pago de los gastos razonablemente incurridos por la parte que hizo la oferta desde la fecha en que la entregó, a menos que el Tribunal Judicial determine que circunstancias especiales justifican la imposición de una sanción distinta. La sanción puede ser adicional a las costas determinadas de acuerdo con lo dispuesto en el Art. $27^{\circ}$ de estas Normas..

(g) Si los términos de una oferta aceptada no se cumplen dentro de un período de tiempo razonable, quien la aceptó puede escoger entre requerir su cumplimiento o continuar con el proceso ante el Tribunal Judicial.

\section{Medidas cautelares}

(a) El Tribunal Judicial tiene competencia para expedir, a solicitud de parte, medidas cautelares de innovar o no innovar a fin de prohibir o requerir cierta conducta de cualquier persona que esté sujeta a su jurisdicción, cuando esto sea necesario para preservar el status quo o para evitar un daño irreparable mientras esté pendiente el proceso, a fin de garantizar del mejor modo posible, y en cuanto sea posible, la integridad de la prestación demanda.

(1) Un Tribunal Judicial puede emitir una medida cautelar a petición de parte, sólo ante prueba que demuestre una necesidad urgente de esta medida (peligro en la demora), y que existe pre- 
ponderancia de consideraciones de justicia que apoyen su expedición (verosimilitud del derecho). La parte o persona contra quien se expide la medida cautelar tendrá la oportunidad razonable para expresarse sobre la pertinencia o validez de la medida cautelar una vez que sea así expedida.

(2) El Tribunal Judicial, luego de escuchar a las partes interesadas, puede expedir, renovar, modificar o dejar sin efecto una medida cautelar, dado su carácter provisorio, transitivo, instrumental y variable, en los términos que sean necesarios para mantener el status quo o evitar daño irreparable.

(3) El Tribunal Judicial puede requerir la presentación de una fianza u otra medida adecuada como necesaria contracautela, a fin de proteger del modo más apropiado la indemnización al demandado o a la persona contra quien se expidió la medida cautelar de que se trate.

(b) Una medida cautelar así adoptada puede prohibirle a una persona, sobre la cual el Tribunal Judicial tiene jurisdicción, que transfiera bienes, independientemente de dónde éstos estén localizados, mientras esté pendiente el proceso. También el Tribunal Judicial puede requerir a una parte que divulgue, sin demora innecesaria, la localización de sus activos, esto incluye los activos bajo su control, y bajo el control de personas cuya identidad o paradero son relevantes. Esta autoridad no impide que una parte obtenga un embargo o un remedio similar permitido bajo la ley del foro, pero el Tribunal Judicial puede emitir un medida cautelar, de acuerdo con el proceso previsto en la Subsección (a), para terminar, suspender o limitar dicho embargo.

(c) Cuando lo bienes o activos estén localizados en el extranjero, el cumplimiento con la orden de medida cautelar estará regido por la ley del país donde los bienes o los activos estén localizados, y mediante una medida cautelar que deberá emitir el Tribunal Judicial competente del país de que se trate.

\section{Determinaciones preliminares y comparescencia inicial}

(a) El Tribunal Judicial, a petición de parte, o "exofficio", tan pronto como sea posible, determinará: 
(1) Que el proceso no está regido por el imperio de estas Normas, que el Tribunal Judicial no tiene competencia para resolver el proceso, o que el Tribunal Judicial no tiene competencia sobre alguna de las partes de proceso;

(2) Que una alegación o contestación u otro proceso utilizado por una parte no cumplió con estas Normas o es de alguna forma irregular;

(3) Que la demanda o contestación de alguna parte es nula en cuanto al derecho sustantivo o no está sostenida o apoyada por prueba suficiente para permitir que se emita una sentencia a favor de esa parte. Sin embargo, el Tribunal Judicial, antes de hacer esta determinación, tiene que tomar en cuenta el derecho de esa parte a hacer descubrimiento de prueba bajo estas Normas.

(4) Otros asuntos de derecho sustantivo o procesal necesarios para poder resolver la causa.

(b) Una vez hechas las determinaciones según lo dispuesto en la Subsección (a), el Tribunal Judicial puede conceder a la parte contra quien se tomó la determinación, una oportunidad razonable para enmendar su demanda o contestación, si la deficiencia puede ser remediada mediante enmienda.

(c) El Tribunal Judicial ordenará a cada parte que divulgue la información descrita e la Norma 14.

(d) Los abogados de las partes asistirán a todas las audiencias ordenadas por el Tribunal Judicial. El Tribunal Judicial puede ordenar que las partes asistan o, en el caso de una organización o persona jurídica, que un representante habilitado de la misma asista.

\section{Divulgación y exhibicion de la prueba}

(a) Una parte, antes de exigir divulgación o exhibición de prueba de otra parte, divulgará todos los documentos que tenga la intención de presentar como prueba, y proveerá un resumen del testimonio de cada testigo que tenga la intención de presentar. Con este propósito, el abogado de una parte puede entrevistar potenciales testigos.

(b) Una parte puede requerir que cualquier persona, incluso un tercero según lo dispuesto en la Norma 24, actúe cualquier información 
no privilegiada, que sea relevante al caso y que sea admisible en un proceso, como la siguiente:

(1) Documentos y otros expedientes de información que sean relevantes a los asuntos en controversia y que estén identificados específicamente o que pertenezcan a categorías específicamente definidas.

(2) La identidad y el paradero de personas que tengan conocimiento personal de los asuntos en controversia.

(3) La identidad de cualquier perito que otra parte tenga la intención de presentar y una declaración que contenga la opinión del perito respecto a los asuntos en controversia.

(c) Cualquier persona puede invocar la protección contra la autoincriminación que se reconozca bajo la ley del foro. Sin embargo, no se considerará un objeción válida que la información sea adversa a la parte que la provee.

(d) Cuando exista una controversia sobre la condición física o mental de una persona sujeta a la jurisdicción del Tribunal Judicial, éste puede ordenar que se someta a la persona a un examen médico razonable.

(e) El Tribunal Judicial podrá ordenar que se produzca la actuación de prueba adicional relevante a la divulgación de cualquier asunto, no privilegiado, cuya presentación sea necesaria en interés de la justicia, incluyendo la deposición de una parte $u$ otros testigos. Dicha deposición se tomará según lo dispuesto en la Norma 15.

(f) Las peticiones de descubrimiento de prueba se harán de la siguiente manera:

(1) Las peticiones iniciales del demandante se presentarán en la demanda o dentro del término de sesenta (60) días a partir de que el demandado presente su contestación. Las peticiones iniciales de los demandados se presentarán en la contestación o dentro del término de quince (15) días a partir de la presentación de la petición de los demandantes.

(2) Se podrá hacer una segunda petición dentro del término de treinta (30) días a partir del momento en que la parte contraria haya cumplido con las peticiones iniciales. 
(3) Se podrá hacer una petición adicional con el propósito de descubrir prueba cuya necesidad no pudo razonablemente ser anticipada en las peticiones anteriores.

(4) El Tribunal Judicial podrá autorizar peticiones adicionales.

(5) La contestación a una petición de descubrimiento de prueba se presentará dentro de un término de treinta (30) días, a menos que se acuerde lo contrario o el Tribunal Judicial lo ordene.

(g) A petición de parte, el Tribunal Judicial puede designar un oficial especial para presidir la toma de una deposición o supervisar la actuación de documentos o de alguna otra manera auxiliar en la supervisión del cumplimiento con esta Norma.

(h) A fin de hacer efectiva una petición de descubrimiento, el Tribunal Judicial podrá:

(1) Hacer inferencias adversas, respecto a los hechos en controversia, en contra de una parte que incumpla con la petición de descubrimiento de prueba;

(2) Utilizar las medidas autorizadas en las Normas 23 y 24;

(3) Desestimar reclamos, defensas o alegaciones para las cuales el descubrimiento de prueba es relevante;

(4) Emitir una Sentencia de desestimación con perjuicio contra un demandante o una sentencia en rebeldía contra un demandado.

\section{Declaración de parte y testimonio por o declaración jurada}

(a) Se podrá realizar una declaración cuando el Tribunal Judicial lo ordene en interés de la justicia según lo dispuesto en la Norma 14 (e).

(b) El testimonio se presentará bajo afirmación según lo dispuesto en la Norma 22(b)(2) y será transcrito verbatim o mediante grabación de audio o vídeo, según las parte lo acuerden o el Tribunal Judicial ordene. El costo de la transcripción será pagado por la parte que solicitó la deposición, a menos que el Tribunal Judicial ordene lo contrario.

(c) La declaración se tomará en el momento y lugar que las partes acuerden o el Tribunal Judicial ordene. Se notificará por escrito a todas las partes y al Tribunal Judicial, el lugar y la hora de la declaración con (30) días de antelación. El interrogatorio se llevará se- 
gún lo dispuesto en la Norma 22. Previa a la declaración, el Tribunal Judicial podrá realizar preguntas suplementarias que considere necesarias para el proceso, y que deberán ser obligatoriamente absueltas por el declarante.

(d) La declaración podrá incorporarse como testimonio en el expediente del caso, si las partes así lo acuerdan o el Tribunal Judicial así lo ordena.

(e) Una parte puede presentar un affidávit o declaración jurada firmada por alguien que no es parte, que afirma decir la verdad, y que contenga declaraciones sobre hechos relevantes al proceso. El Tribunal Judicial, a su discreción, podrá considerar dichas declaraciones como si hubieran sido provistas mediante testimonio oral. Si otra parte niega la veracidad de las declaraciones presentadas mediante affidávit o declaración jurada, esa parte puede solicitar al Tribunal Judicial la comparecencia personal del autor del affidávit o la declaración jurada en la audiencia plenaria del Tribunal Judicial.

16. Ordenes protectoras respecto al descubrimiento de prueba y la divulgación

(a) El Tribunal Judicial, «exofficio», o a petición de parte o un tercero legitimado que esté obligado a hacer la exhibición de una prueba o su divulgación conforme a las Normas 14 ó 24, puede limitar o prohibir la divulgación o la exhibición de la prueba cuando sea evidente que cumplir con tal petición será oneroso, o sea improbable que se obtenga prueba relevante admisible con esta evidencia, o se requiera la presentación de prueba protegida por un privilegio o limitación legal.

(b) Cuando la información que se pretende sea divulgada es un secreto comercial o de negocio, o cuando su divulgación pública pueda causar daño o afectar el honor o la buena reputación de una persona, sea o no parte del proceso, y que puede ser evitada o mitigada mediante una medida cautelar apropiada, el Tribunal Judicial deberá conceder dicha orden cautelar exofficio o a petición de parte.

(c) Cuando sea útil para que el Tribunal Judicial pueda ejercer su autoridad bajo esta Norma, la prueba solicitada puede ser examinada por el Tribunal Judicial en las deliberaciones. 


\section{Audiencias posteriores complementarias}

(a) El Tribunal Judicial puede ordenar una o más audiencias posteriores de orden complementario. El Tribunal Judicial podrá:

(1) Ordenar que se añadan, eliminen, o revisen los reclamos, defensas y controversias a la luz de las alegaciones de las partes en esta etapa de los procesos.

(2) Ordenar la consideración y decisión separada de una o más controversias en el pleito. El Tribunal Judicial emitirá auto interlocutorio sobre la controversia y su relación con el resto del proceso.

(3) Ordenar la consolidación por acumulación de los procesos pendientes, sea bajo estas Normas o las Normas del foro interno de que se trate, cuando éstos se refieran al mismo negocio o negocios relacionados, y cuando la consolidación por acumulación facilite el proceso y la decisión. La sentencia se referirá a todos los procesos así acumulados.

(4) Tomar decisiones sobre la admisibilidad y pertinencia de la prueba ofrecida.

(5) Determinar la secuencia o el orden para la presentación de testigos y peritos en la audiencia.

(6) Fijar la fecha para la audiencia plenaria.

(7) Emitir otras órdenes y resoluciones para concluir el proceso en cumplimiento del principio de la celeridad procesal.

(b) El Tribunal Judicial puede sugerir que las partes consideren la posibilidad de una transacción, total o parcial, o el uso en las mismas condiciones de mediación o arbitraje de derecho.

\section{Idioma}

(a) El proceso, incluyendo los documentos, instrumentos, actuaciones orales y la actuación y ejecución de la prueba, se realizarán en el idioma de la sede del Tribunal Judicial, excepto en la medida en que el Tribunal Judicial, con la anuencia de las partes, determine lo contrario. 
(b) Se limitará la traducción a las partes relevantes de documentos largos o voluminosos, seleccionados por las partes o el Tribunal Judicial.

(c) El costo de la traducción será pagado por la parte que presenta la persona o el documento, a menos que el Tribunal Judicial ordene lo contrario.

\section{Relevancia y admisibilidad de prueba pertinente}

(a) Toda prueba relevante a asuntos en controversia será admisible en su actuación, incluso la prueba accesoria.

(b) Cualquier persona que tenga capacidad civil y jurídica estará habilitada para actuar prueba válida en el proceso, incluso las partes.

(c) Una parte puede llamar como testigo a cualquier persona cuyo testimonio sea relevante y admisible, incluso a la parte misma. El Tribunal Judicial puede exofficio citar a cualquier persona sujeto a las mismas condiciones.

(d) Las partes pueden presentar en la determinación de los hechos del proceso cualquier documento o instrumento jurídico relevante o prueba real o demostrativa. El Tribunal Judicial puede ordenar a cualquier parte o a un tercero presentar cualquier documento o instrumento jurídico, o prueba real o demostrativa que esté en el ámbito jurídico de esa persona.

\section{Prueba pericial}

(a) El Tribunal Judicial puede designar un perito o panel de peritos cuando, a su discreción, por su experiencia, ciencia u oficio el testimonio pericial sea considerado útil para resolver las controversias o las pretensiones del proceso. El testimonio pericial puede referirse a las Normas de derecho nacional de orden interno, al derecho extranjero y al derecho internacional. El Tribunal Judicial determinará las controversias o asuntos que serán discutidos por el perito, y las pruebas, evaluaciones u otros procesos que podrá utilizar. El Tribunal Judicial podrá emitir las órdenes necesarias para facilitar la investigación y el informe del perito y puede especificar la forma en que éste preparará su informa.

(b) Una parte puede designar su propio perito o panel de peritos sobre una controversia o asunto. Los peritos de las partes tendrán dere- 
cho a participar en $\mathrm{u}$ observar las pruebas, evaluaciones $\mathrm{u}$ otros procesos llevados a cabo por el perito del Tribunal Judicial. El Tribunal Judicial puede ordenar a todos los peritos que discutan entre sí antes de la presentación de sus opiniones. Los peritos de las partes pueden presentar sus opiniones al Tribunal Judicial de la misma forma en que el perito del Tribunal Judicial presentó su informe.

(c) Las costas y gastos del perito del Tribunal Judicial serán asumidos directamente por la parte que solicita la investigación, o por el demandante cuando el Tribunal Judicial solicita la investigación, a menos que el Tribunal Judicial ordene lo contrario. Cada parte pagará por el perito que contrate.

\section{Privilegios en la prueba}

(a) No se admitirá la actuación de prueba protegida legalmente por los siguientes privilegios:

(1) Privilegio del secreto de la profesión legal; y,

(2) Comunicaciones privadasen la negociación de una transacción.

(b) No se admitirá la actuación de prueba de información protegida por otros privilegios reconocidos por la ley del lugar donde ocurrió la comunicación, a menos que el Tribunal Judicial determine que la necesidad de esa prueba para determinar la verdad es más significativa que la necesidad de mantener la confidencialidad de la información. Dicha prueba será actuada en sesión privada del Tribunal Judicial, pero en presencia de las partes, los terceros legitimados y de sus respectivos abogados. El Tribunal Judicial ordenará la protección de la confidencialidad del material privilegiado.

(c) La reclamación de un privilegio respecto a un documento describirá el documento con suficiente detalle para permitir a la otra parte controvertir el reclamo.

(d) El privilegio podrá ser renunciado por o en representación de la persona con derecho a beneficiarse del mismo. Una parte renuncia a un privilegio cuando falla en hacer una objeción oportuna a una pregunta o petición de descubrimiento de prueba que requiere la divulgación de comunicaciones privilegiadas. El Tribunal Judicial, 
en interés de la justicia, puede relevar a una parte de su renuncia a un privilegio.

\section{Audiencia plenaria}

(a) Se recibirá la prueba en una sola audiencia, o en audiencias en días judiciales consecutivos, excepto cuando el Tribunal Judicial ordene lo contrario para la conveniencia de las partes o las personas que presentan la prueba o la administración de justicia.

(b) La prueba en la audiencia plenaria se recibirá de acuerdo con las siguientes Normas:

(1) Una persona que presenta una prueba debe jurar, o prometer por su honor, que dirá la verdad. El Tribunal Judicial determinará los términos de la del juramento o de la promesa por el honor, cuando corresponda.

(2) Una persona que presenta prueba será objeto de interrogatorio directo por la parte que solicitó su comparecencia. A los abogados de las otras partes se les permitirá contrainterrogar al testigo. El Tribunal Judicial puede permitir interrogatorios directos y contrainterrogatorios adicionales. El Tribunal Judicial excluirá, a petición de parte o exofficio, prueba irrelevante y preguntas manifiestamente inapropiadas. El Tribunal Judicial evitará que se afecte el honor o la buena reputación o que se acose a la intimidad de las personas que presentan prueba.

(3) El Tribunal Judicial podrá en cualquier momento interrogar un testigo para aclarar su testimonio, incluso mediante preguntas adicionales luego que las partes hayan interrogado.

(4) Una persona citada por el Tribunal Judicial para presentar prueba será interrogada primero por el Tribunal Judicial. Luego la persona podrá ser interrogada por los abogados de las partes.

(5) El interrogatorio directo puede referirse a cualquier controversia o asunto relevante del pleito. El contrainterrogatorio podrá referirse a cualquier controversia o asunto discutido en el interrogatorio directo, a menos que el Tribunal Judicial permita un alcance más amplio.

(6) Serán admisibles las actuaciones de las declaraciones hechas por una parte fuera del registro del 'Tribunal Judicial, si al momento que las declaraciones se hicieron eran contrarias al interés de esa parte. 
(7) La credibilidad de un testigo o perito podrá ser impugnada mediante el interrogatorio de una parte o la consideración de declaraciones anteriores inconsistentes u otra prueba que pueda afectar la credibilidad de un testigo. Cualquier parte puede impugnar a cualquier testigo. El Tribunal Judicial puede hacer preguntas que afecten la credibilidad de la persona. La impugnación sólo se permite respecto a controversias o asuntos materiales y sólo si tiende a crear serias dudas sobre la confiabilidad del testimonio.

(8) El Tribunal Judicial puede permitir la impugnación de la autenticidad o corrección de un documento o un artículo de prueba real o demostrativa.

(9) El Tribunal Judicial puede controlar la confiabilidad de la prueba científica y técnica y puede determinar el proceso y las técnicas que se utilizarán con tales propósitos.

(10) El Tribunal Judicial determinará si el testimonio de un perito es lo suficientemente confiable como para ser admitido en evidencia.

23. Poderes y remedios relacionados a la admisión de prueba en evidencia

El Tribunal Judicial podrá a petición de parte o "exofficio":

(a) Excluir prueba irrelevante, impertinente o redundante o la prueba cuya presentación imponga costo, cargo o dilación excesiva o indebida.

(b) Hacer inferencias adversas a partir de la negativa de una parte a presentar testimonio o a presentar un testigo o producir un documento $\mathbf{u}$ otro artículo en evidencia que la parte pudo haber presentado.

(c) Imponer una multa o hallar en desacato cualquier persona que, sin justificación, y una vez se le haya ordenado con acuerdo a la ley, no se presenta a ofrecer prueba, o se niega a contestar preguntas apropiadas, o falla en producir un documento u otro artículo en evidencia o que de otra manera obstruye la administración de la justicia.

(d) En interés de la justicia, relevar a una parte de las consecuencias de su incumplimiento con las Normas sobre la evidencia. 


\section{Ordenes dirigidas a terceros}

(a) El Tribunal Judicial puede ordenar a personas sujetas a su jurisdicción que no son partes en el proceso:

(1) Que cumplan con una medida cautelar emitida de acuerdo con lo dispuesto en la Norma 12(a);

(2) Que retengan fondos u otros bienes cuyo título esté en disputa en el proceso, y que desembolsen los mismo sólo de acuerdo con una orden del Tribunal Judicial;

(3) Que presten testimonio en la fase de descubrimiento de prueba o en la audiencia.

(4) Que produzcan documentos u otras cosas como evidencia.

(b) El Tribunal Judicial puede requerir a una parte que solicita se expida una orden dirigida a un tercero, que provea indemnización por los gastos que implica el cumplimiento con la orden.

(c) Una orden dirigida contra un tercero puede hacerse efectiva mediante la imposición de una penalidad monetaria por incumplimiento y cualquier otra medida legal autorizada por el Tribunal Judicial, tales como desacato o la confiscación del material probatorio u otros aspectos. Véase también la Norma 32.

\section{Expediente del proceso}

(a) El Secretario del Tribunal Judicial conservará un resumen del proceso, si así lo ordena el Tribunal Judicial.

(b) A petición de cualquier parte que pague los gastos del mismo, se conservará una transcripción verbatim o una grabación en audio o vídeo del proceso.

(c) Una parte puede asumir el costo de producir una transcripción verbatim

\section{Deliberación final y sentencia}

(a) Al finalizar la presentación de la prueba, cada parte tiene derecho a presentar un resumen escrito de sus alegaciones. Con el permiso del Tribunal Judicial, todas las partes pueden realizar una exposi- 
ción oral final en la audiencia que se señale para este efecto. El Tribunal Judicial puede permitir que los abogados de las partes, entre ellos y con el Tribunal Judicial, discutan de forma oral y brevemente sobre las controversias o asuntos principales del caso. Los abogados de las partes estarán obligados a responder de modo sucinto y concreto a las preguntas que les formulen los miembros del Tribunal Judicial, si así lo tienen por conveniente.

(b) El Tribunal Judicial emitirá su sentencia por escrito al final de la última audiencia, cuyas principales consideraciones y parte resolutiva será leída por el Secretario del Tribunal Judicial. Las controversias de hecho se determinarán de acuerdo a la ley aplicable que gobierna el valor de prueba requerido. Cuando sea necesario, el Tribunal Judicial deliberará en privado antes de emitir su sentencia. Cuando sea necesario por la complejidad del caso, el Tribunal Judicial puede ordenar un receso en las deliberaciones, fijando fecha para una nueva audiencia para emitir su sentencia en los términos ya indicados.

(c) El Tribunal Judicial publicará, en el plazo más breve posible, una opinión escrita en la que incluya las principales conclusiones de hecho basadas en la prueba valorada, el razonamiento en que se apoyan, y las principales normas legales en que se fundamenta la decisión.

\section{Costas}

(a) Cada parte pagará sus propias costas y gastos, incluyendo los gastos del Tribunal Judicial, honorarios de abogados y gastos incidentales.

(b) La parte derrotada reembolsará a la parte vencedora sus costas y gastos, pero la determinación de las costas puede suspenderse si se emite una orden de paralización del cumplimiento con la sentencia según lo dispuesto en la Norma 32(c). La parte que venció en el proceso someterá una declaración certificada por la parte o su abogado de sus costas y gastos dentro del término de treinta (30) días a partir de que se dictó sentencia. La parte derrotada pagará sin demora la cantidad solicitada, por el sólo mérito de su requerimiento, con excepción de aquellos gastos o costas que intereses cuestionar. Los gastos o costas en disputa se determinarán por el Tribunal Judicial o por cualquier otro proceso que las partes acuerden. 
(c) El Tribunal Judicial puede limitar el reembolso de costas y gastos contra una parte derrotada, si sus argumentos legales o de hecho tenían base razonable. El Tribunal Judicial puede imponer una penalidad que no exceda el doble de la cantidad dispuesta en la Subsección (b) contra una parte que el Tribunal Judicial determine no tenían base razonable para cuestionar los gastos y costas.

(d) Si se revisa en apelación la sentencia, las normas y el proceso mencionados en esta Norma aplicarán de igual manera a las costas y gastos incurridos en relación con la apelación.

(e) Si la ley del derecho interno lo autoriza, el Tribunal Judicial puede requerir a una parte que no es residente la prestación de una fianza o depósito para cubrir las costas y gastos.

\section{Actos procesales posteriores a la sentencia}

\section{La apelación}

(a) Sólo la sentencia final de un Tribunal Judicial de primera instancia es apelable, con excepción de lo dispuesto en la Subsección (b).

(b) Una orden de un Tribunal Judicial de primera instancia que conceda o niegue un medida cautelar solicitada bajo la Norma 12, está sujeta a revisión inmediata en vía de apelación parte. El medida cautelar se mantendrá en efecto durante el trámite de la apelación, a menos que el Tribunal Judicial apelativo ordene lo contrario.

(c) Las órdenes del Tribunal Judicial, que no sean una sentencia final o una orden apelable según la Subsección (b), sólo estarán sujetas a apelación inmediata si así lo permite el Tribunal Judicial de primera instancia o mediante orden del Tribunal Judicial apelativo. Se podrá conceder dicho permiso cuando una apelación inmediata resuelva una controversia o asunto legal de importancia general o de importancia especial para el proceso inmediato.

(d) La revisión vía de apelación estará limitada a los términos de la misma, a los reclamos, defensas y reconvenciones presentadas ante el Tribunal Judicial de primera instancia. No se admitirá ninguna nueva prueba que haya estado disponible de modo previo, excepto si ello es necesario para evitar un fracaso manifiesto de la justicia. 


\section{Trámite posterior a la apelación}

De acuerdo con la ley del derecho interno del Estado de que se trate, excepcionalmente se podrá recurrir o impugnar de alguna otra forma extraordinaria la decisión de un Tribunal Judicial de segunda instancia. La revisión del segundo Tribunal Judicial impugnativo atenderá únicamente las controversias o asuntos de derecho sustantivo o procesal. Las controversias de hecho no serán consideradas nuevamente. No se admitirá nueva prueba, ni reclamos o defensas adicionales. El segundo Tribunal de Justicia impugnativo se reservará, conforme a su ley interna, la admisibilidad por el fondo y por a forma de una segunda revisión impugnativa.

\section{Impugnación de la sentencia en procesos posteriores}

Una sentencia sólo podrá anularse mediante un nuevo proceso y sólo si se demuestra que el solicitante actuó con la debida diligencia, y que, además:

(a) La sentencia se emitió sin competencia sobre la materia o sin jurisdicción sobre la parte que solicita la anulación; o

(b) La sentencia se obtuvo mediante fraude al Tribunal Judicial; o

(c) Existe prueba disponible que no lo estaba previamente y que llevaría a una decisión distinta; o

(d) La sentencia constituye una clara violación al debido proceso legal y/o fracaso manifiesto de la justicia.

\section{Finalidad}

Una sentencia no está sujeta a ser reexaminada en cuanto a cumplimiento con las normas procesales o sustantivas una vez expire el plazo ordinario para su revisión en vía de apelación, a excepción de lo dispuesto en la Norma 30.

7. Cumplimiento y ejecución de la sentencia

(a) Una sentencia final, incluso una orden de medida cautelar cualquiera sea su denominación o alcances, será ejecutada inmediatamente, a menos que su efectividad haya sido suspendida según lo 
dispuesto en la Subsección (c). En particular, una sentencia final puede ser ejecutada de inmediato mediante el embargo de bienes pertenecientes a, o de una obligación debida a, la persona contra quien recayó la sentencia.

(b) Si una persona contra la cual recayó la sentencia no cumple con ésta en el período de tiempo especificado, o dentro de treinta (30) días a partir de que la sentencia advino final y firme si no se especificó un período, el Tribunal Judicial puede imponer las medidas coercitivas pertinentes que determine el derecho interno del estado de que se trate para requerir el cumplimiento eficaz con la sentencia. Estas medidas pueden incluir la exhibición obligatoria de los activos y una penalidad pecuniaria al obligado, a pagarse a la parte contraria o a quien el Tribunal Judicial determine.

(1) La persona que tenga derecho a exigir el cumplimiento de la sentencia, puede solicitar esta sanción.

(2) La penalidad por el incumplimiento incluirá las costas y gastos incurridos por la parte que solicita el cumplimiento con la sentencia, incluso los honorarios de abogados, y puede también incluir una penalidad por desacato al Tribunal Judicial, que no exceda el doble de la cantidad impuesta en la sentencia.

(3) Si la persona contra quien se emitió la sentencia persiste en su negativa a cumplir, el Tribunal Judicial podrá imponerle penalidades adicionales.

(4) No se impondrán penalidades a una persona que demuestre al Tribunal Judicial incapacidad financiera o de algún otro tipo para cumplir con la sentencia.

(5)El Tribunal Judicial puede ordenar a terceros que divulguen información relacionada con los activos del deudor.

(c) El Tribunal Judicial de primera instancia o el Tribunal Judicial de apelación pueden, por solicitud de la parte contra quien se emitió la sentencia, emitir una orden de suspensión del cumplimiento de la sentencia mientras dure la apelación, si ello es estimado necesario por el Tribunal Judicial en aras del interés de la justicia.

(d) El Tribunal Judicial puede exigir una fianza razonable u otra garantía suficiente al apelante como condición para emitir una orden de suspensión de la sentencia recurrida, como condición para denegar la solicitud de paralización. 
8. Deber de cooperación de jurisdicción

Los Tribunales Judiciales de un Estado que ha reconocido estas Normas deberán, y los Tribunal Judiciales de otros Estados podrán, cumplir y hacer cumplir tantas órdenes como se requieran para la adecuada cooperación de jurisdicción en los procesos en otro Estado parte.

14 de enero de 1999 